\title{
Neuromuscular electrical stimulation keeps a tetraplegic subject in his chair: A case study
}

\author{
H Rischbieth ${ }^{1}$, M Jelbart ${ }^{1}$ and R Marshall ${ }^{2}$ \\ ${ }^{1}$ Functional Electrical Stimulation Clinic, Hampstead Centre, 207-255 Hampstead Road, Northfield, South Australia, \\ 5085; '2 Spinal Injuries Unit, Hampstead Centre, 207-255 Hampstead Road, Northfield, South Australia, 5085
}

\begin{abstract}
Pressure ulcers are an important complication of spinal cord injury which place an enormous burden on society due to their financial, psychosocial, and vocational implications. Although they are now rarely fatal, they can still have devastating consequences, often needing prolonged hospitalisation to be properly managed. This study reviews the use of electrical stimulation to overcome increasing debility due to sacral pressure ulcers and saddle soreness in a man with tetraplegia. After 24 months of regular cyclic stimulation he had increased circumferential dimensions across his buttocks by up to $21 \%$, and increased his sitting tolerance.
\end{abstract}

Keywords: NMES; FES; pressure ulcer; tetraplegia; care study

\section{General background}

Pressure ulcers have long been recognised as one of the more serious and costly complications of spinal cord injury, occurring in up to $80 \%$ of those with a spinal cord injury. ${ }^{1}$ Their prevention and management is a constant demand on the individual concerned, other family members, carers, and hospital staff. ${ }^{2}$ Significant, negative psychological effects of these complications have been recognised by a number of authors. ${ }^{1,3-5}$

The financial burden of hospitalisation for pressure ulcers amounts to many thousands of dollars per year, and has been estimated to range from \$US15 000 to $\$ 70000$ for each ulcer. ${ }^{3}$ Another complication is a loss of physical condition associated with the imposed bed rest, ${ }^{6}$ making return to the previous level of function a difficult, lengthy and arduous procedure.

Despite these factors, there is little really known about the epidemiology of pressure ulcers - those most at risk, the influence of time since injury, and the influence and inter-relationship of the multitude of risk and preventive factors. ${ }^{3}$

Byrne and Salzberg (1996) identified more than 50 risk factors, which they separated into categories. Their 15 major risk factors were divided into three categories

1. Severity of spinal cord injury;

2. Pre-existing conditions; and

3. Malnutrition and anaemia.

Other potential risk factors identified included medical factors, past history, gender and ethnicity,

Correspondence: H Rischbieth medications, and issues related to movement, socioeconomic, psychological and nutritional status. ${ }^{1}$

This case study describes the use of neuromuscular electrical stimulation in the management of recurrent sacral pressure ulcers in a man with tetraplegia.

\section{Subject}

Mr P sustained a C6 cord injury in 1966, leaving him with some poorly defined saddle sensation, but no motor function below his neurological level.

Due to severe spasticity, which interfered with and impaired many of his independent activities, he had a Bischoff myelotomy in 1979. This led to wasting of his leg muscles, but enabled him to maintain his social interactions.

Between 1987 and 1993 he had six hospital admissions for management of pressure ulcers, with admissions ranging from $1-10$ weeks, and totalling 25 weeks. They had left extensive scars on his saddle area, which made sitting increasingly uncomfortable, so that he was unable to tolerate sitting longer than $30 \mathrm{~min}$. All this occurred despite the efforts of our Seating Clinic who attempted to improve his sitting tolerance.

Electrical stimulation has been identified as the only electrical modality available to physiotherapists which increases skin blood flow. ${ }^{7}$ Similarly, electrical stimulation to muscles of the lower limbs has been advocated for improving skin perfusion following spinal cord injury. ${ }^{8-11}$ The authors had observed similar results in other clients using electrical stimulation, and therefore proposed a trial of neuromuscular electrical stimulation (NMES) applied to Mr P's gluteal muscles. It was 
unclear whether lower motor neuron innervation to the region may have been compromised during the previous neurosurgical procedures.

Mr P was very keen to pursue electrical stimulation, having become aware of some of its potential benefits through the Spinal Cord Injury Unit, and through anecdotal information from other outpatients. He presented to the Functional Electrical Stimulation (FES) Clinic in Adelaide in September 1994.

\section{Method}

Before the trial of stimulation, dimensions were measured, around the buttocks between greater trochanters, and between each greater trochanter and opposite anterior superior iliac spine (ASIS) (Figure 1).

Despite the myelotomy, stimulation was successful, and weak contractions were evident in both gluteus maximus muscles. Suitable stimulation parameters were therefore established, and a home stimulation programme was commenced. In keeping with clinic policy, $\mathrm{Mr} \mathrm{P}$ was lent a portable stimulator for use three times daily and his wife received training in the correct application of FES to the gluteal muscles.

Stimulation sessions were for $15 \mathrm{~min}$, three times a day, at a preset duty cycle, with output intensity initially limited to $65 \%$. This produced a visible contraction which was identified and monitored by family members who administered the home program. Progress was monitored weekly, when the response was observed throughout the $15 \mathrm{~min}$ of cyclic stimulation. Fatigue was a limiting factor during the

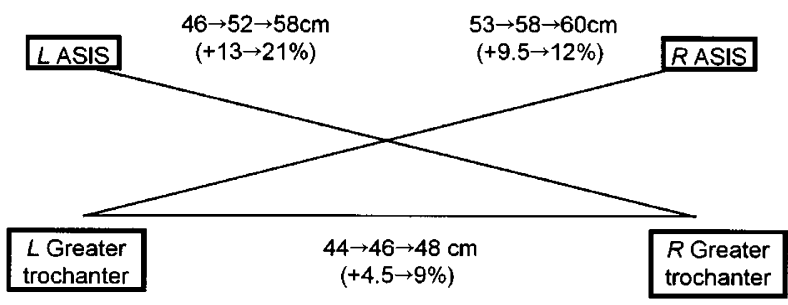

Figure 1 Dimensions across the buttocks before, after 7 and after 24 months of electrical stimulation with absolute values in parentheses

Table 1 Stimulation parameters, and their progression

\begin{tabular}{lcccc}
\hline & & & & $7-24$ \\
Parameter & Start & 1 month & 4 months & months \\
\hline Frequency & $30 \mathrm{pps}$ & $30 \mathrm{pps}$ & $30 \mathrm{pps}$ & $30 \mathrm{pps}$ \\
Duty cycle & $10: 15 \mathrm{~s}$ & $10: 15 \mathrm{~s}$ & $10: 8 \mathrm{~s}$ & $10: 8 \mathrm{~s}$ \\
Ramps & $4: 2 \mathrm{~s}$ & $4: 2 \mathrm{~s}$ & $4: 2 \mathrm{~s}$ & $4: 2 \mathrm{~s}$ \\
Intensity & $65 \%$ & $80 \%$ & $100 \%$ & $100 \%$ \\
Session & & & & \\
$\quad$ time & $15 \mathrm{~min} \mathrm{tds}$ & $15 \mathrm{~min} \mathrm{tds}$ & $15 \mathrm{~min} \mathrm{tds}$ & $30 \mathrm{~min} \mathrm{bd}$ \\
\hline
\end{tabular}

first month which was reflected in the initial stimulation programme. Stimulation parameters were gradually progressed as strength and endurance of stimulated contractions increased over the subsequent months (Table 1).

\section{Results}

After 1 month of stimulation $\mathrm{Mr} \mathrm{P}$ reported much less pain in sitting, and this enabled him to increase his comfortable sitting time (from $30 \mathrm{~min}$ before onset of discomfort prior to commencing the stimulation programme, to more than $2 \mathrm{~h}$ ). The atrophic scarred areas, which had become red and angry if he sat for more than $30 \mathrm{~min}$, ceased being erythematous, and became more pliable and mobile. These changes were consistent with maturation of the surgical scars, which had not occurred with conventional management.

This progress continued, using the same stimulation parameters, and after 2 months he was able to sit all day (excluding time spent lying prone during stimulation sessions). Output intensity was then increased to $100 \%$ to recruit more motor units, and increase the strength of the stimulated contraction. ${ }^{12}$

At this point in time he felt confident enough to leave on an overseas holiday for several weeks, and had no problems with skin breakdown despite sitting for long unbroken periods. He continued the stimulation program while away, and as his skin condition and muscle endurance both improved during this time the duty cycle was progressed on his return.

Dimensions across the buttocks were remeasured after 7 months of stimulation, when they had increased by between $4.5 \%$ and $13 \%$ (Figure 1). Stimulation parameters were progressed again, with duration of each session increased from 15-30 min, now performed twice daily (Table 1). After another 17 months, having continued with the same stimulation programme, dimensions were remeasured, and showed further increases, by between $9 \%$ and $21 \%$ (Figure 1). During this time Mr P had had a number of small areas of broken skin on his buttocks, resulting mainly from trauma during transfers. However, these were all managed at home, and required less than 1 week of bedrest, which was a great improvement on previous similar events prior to starting the stimulation programme.

\section{Discussion}

A number of possible alternatives are suggested as explanation for these increases, including a collection of local oedema, increased adipose tissue in the area, and hypertrophy of the underlying musculature.

Local oedema was excluded as there was no clinical evidence of it, nor could it explain the maturation of scars and much faster healing rate of recent areas of broken skin.

An increase in underlying fat seems somewhat simplistic, as it also fails to account for maturation 
of scar tissues and much faster healing rate of recent areas of broken skin.

Hypertrophy of the underlying musculature, on the other hand, can only occur in response to increased muscle activity, with an associated increased demand for circulation. Such an increase in blood supply will also facilitate maturation of scars, improved comfort in sitting, and greater healing responses.

\section{Conclusion}

The results in this case study support previous findings, ${ }^{8-11}$ that increased muscle mass in, and circulation through the gluteal region may occur in response to chronic electrical stimulation. This proposition is supported by the improved sitting tolerance, reduced frequency and severity of pressure sores, and completion of the healing processes of surgical scars demonstrated by $\mathrm{Mr} \mathrm{P}$. As he is now able to sit all day he has returned to his previous levels of socialisation, with associated improvement in confidence and self image.

These results also represent significant savings for the health budget. A stimulator has a one-off cost of less than \$US1200, and recurrent costs are likely to be in the order of \$US15 per month, or \$US180 annually, less than the cost of 1 day in hospital.

Any modality which provides a means of maintaining tetraplegic individuals in their chairs will, in the longer term, provide them with greater protection against the debilitating complications of bed rest. Use of electrical stimulation after spinal cord injury is becoming more accepted, but tends to be used as a means of facilitating return of voluntary motor function, gait or functional restoration. The results of this study suggest electrical stimulation can be used in this way to 'keep people in their chairs', and thus warrants further trials, which should include a pain scale, and CT scanning to quantify gains in muscle bulk.

\section{Acknowledgement}

This project was made possible through funding by the Compulsory Third Party (Motor Accident) Fund of the State Government Insurance Commission of South Australia.

\section{References}

1 Byrne DW, Salzberg CA. Major risk factors for pressure ulcers in the spinal cord disabled: a literature review. Paraplegia 1996; 34: $255-263$.

2 Abruzzese RS. Pressure sores: Nursing aspects and prevention. In: Lee BY, Ostrander LE, Cochran GvanB, Shaw WW (eds.) The Spinal cord injured patient: comprehensive management. WB Saunders Co: Philadelphia, 1991; pp 210-222.

3 Graitcer PL, Maynard FM. First colloquium on preventing secondary disabilities among people with spinal cord injury. Centre for Disease Control: Atlanta, 1990.

4 Trieschmann R. Spinal cord injuries: the psychological, social, and vocational adjustment. Demos: New York, 1988.

5 Anderson TP, Andberg M. Psychosocial factors associated with pressure sores. Archives of Physical Medicine and Rehabilitation 1979; 60: 341 - 346 .

6 Downey RJ. Physiology of bed rest. In: Downey JA, Myers SJ, Gonzalez EG, Lieberman JS (eds): The physiological basis of rehabilitation medicine. Boston, Butterworth-Heinemann: 1994; pp $448-454$

7 McMeeken J. Tissue temperature and blood flow: A research based overview of electrophysical modalities. Australian Journal of Physiotherapy 1994; 40th Jubilee Issue: 49-57.

8 Baker LL et al. The effect of electrical stimulation on healing rate in diabetic patients. RESNA 14th Annual Conference, Kansas City, 1991.

9 Glaser RM. Functional neuromuscular stimulation. In: Enders A and Hall M (eds.): Assistive technology sourcebook. RESNA Press: Washington, DC. 1990; pp 439.

10 Levine SP, Kett RL, Cederna PS, Brooks SV. Electric muscle stimulation for pressure sore prevention: Tissue shape variation. Archives of Physical Medicine and Rehabilitation 1990; 71: 210 215.

11 Kralj A, Bajd T. Functional electrical stimulation: Standing and walking after spinal cord injury. CRC Press: Boca Raton, Florida. 1989.

12 Baker LL et al. Neuromuscular Electrical Stimulation - A Practical Guide (3rd edition). Los Angeles, California: Los Amigos Research and Education Institute, Inc, 1993. 